\title{
Cardiac damage in patients with the severe type of coronavirus disease 2019 (COVID-19)
}

Jing Li $i^{*}$, Yinghua Zhang ${ }^{2 \dagger}$, Fang Wang ${ }^{1}$, Bing Liu' ${ }^{1}$, Hui Li ${ }^{1}$, Guodong Tang ${ }^{1}$, Zhigang Chang ${ }^{3}$, Aihua Liu ${ }^{4}$, Chunyi Fu' ${ }^{5}$ You Lv', Jing GaO ${ }^{2^{*}}$ and Jing $\mathrm{Li}^{2,6^{*}}$ (D)

\begin{abstract}
Background: Coronavirus disease 2019 (COVID-19) has become a global pandemic. Studies showed COVID-19 affected not only the lung but also other organs. In this study, we aimed to explore the cardiac damage in patients with COVID-19.
\end{abstract}

Methods: We collected data of 100 patients diagnosed as severe type of COVID-19 from February 8 to April 10, 2020, including demographics, illness history, physical examination, laboratory test, and treatment. In-hospital mortality were observed. Cardiac damage was defined as plasma hypersensitive troponin I (hsTnl) over $34.2 \mathrm{pg} / \mathrm{ml}$ and/or N-terminal-pro brain natriuretic peptide (NTproBNP) above $450 \mathrm{pg} / \mathrm{ml}$ at the age $<50$, above $900 \mathrm{pg} / \mathrm{ml}$ at the age $<75$, or above $1800 \mathrm{pg} / \mathrm{ml}$ at the age $\geq 75$.

Results: The median age of the patients was 62.0 years old. 69 (69.0\%) had comorbidities, mainly presenting hypertension, diabetes, and cardiovascular disease. Fever (69 [69.0\%]), cough (63 [63.0\%]), chest distress (13 [13.0\%]), and fatigue (12 [12.0\%]) were the common initial symptoms. Cardiac damage occurred in 25 patients. In the subgroups, hsTnl was significantly higher in elder patients ( $\geq 60$ years) than in the young (median [IQR], 5.2 [2.2-12.8] vs. 1.9 [1.9-6.2], $p=0.018$ ) and was higher in men than in women (4.2 [1.9-12.8] vs. 2.9 [1.9-7.4], $p=0.018$ ). The prevalence of increased NTproBNP was significantly higher in men than in women (32.1\% vs. 9.1\%, $p=0.006)$, but was similar between the elder and young patients ( $20.0 \%$ vs. $25.0 \%, p=0.554)$. After multivariable analysis, male and hypertension were the risk factors of cardiac damage. The mortality was $4.0 \%$.

Conclusions: Cardiac damage exists in patients with the severe type of COVID-19, especially in male patients with hypertension. Clinicians should pay more attention to cardiac damage.

Keywords: Coronavirus, Severe pneumonia, Cardiac damage

\section{Introduction}

Since the novel coronavirus-severe acute respiratory syndrome coronavirus 2 (SARS-CoV-2) named by the Coronavirus Study Group of the International Committee on

\footnotetext{
*Correspondence: leejingabc@sina.com; gaojing_gao@sina.com; shpxbb@sina.com

${ }^{\dagger}$ Jing Li and Yinghua Zhang contributed equally to this work

1 Division of Cardiology, Beijing Hospital, \#1 Dahua Road, Dongcheng District, Beijing 100730, China

2 Division of Cardiology, Xuanwu Hospital Capital Medical University, \#45

Changchun Street, Xicheng District, Beijing 100053, China

Full list of author information is available at the end of the article
}

Taxonomy of Viruses [1], was discovered in December 2019, it quickly spread throughout China and other countries [2-5]. As of April 30, 2020, SARS-CoV-2 has broken out in 213 countries, areas and territories with 3,090,445 confirmed cases and 217,769 deaths [6]. Coronavirus disease 2019 (COVID-19) caused by SARS-CoV-2 could be classified into four clinical types: mild, moderate, severe and critical types [7]. More than $80 \%$ are mild or moderate with relatively good short-term prognosis due to the self-limiting process according to the study with 44,672 confirmed COVID-19 cases released by the Chinese 
Center for Disease Control and Prevention on February 17, 2020 [8]. However, 6,168 (13.8\%) cases belonged to the severe type and were more likely to develop into the critical type followed by a death rate of $49 \%$, far beyond the average mortality of $2.3 \%$.

Researchers have reported that patients with COVID19 had acute cardiac injury, which is associated with a higher risk of in-hospital mortality [4, 9, 10]. However, studies focusing on cardiac damage in patients with the severe COVID-19 are few.

In this study, we aim to investigate the clinical findings and cardiac damage in patients with the severe type of COVID-19, and hope to contribute to the prevention and treatment.

\section{Methods}

\section{Study population}

We retrospectively collected data of all 100 patients at the Sino-French New Town area of Tongji Hospital, Wuhan, where was aided and charged by the medical team of Beijing Hospital from February 8 to April 10, 2020. Patients were all diagnosed as COVID-19 and classified into the severe type according to the Diagnosis and Treatment of Pneumonia Infected by Novel Coronavirus (5th trial edition) pressed by the General Office of the National Health Commission and the General Office of the National Administration of Traditional Chinese Medicine [7]. Severe type met at least one of the following criteria: (1) dyspnea, respiratory frequency $\geq 30 /$ minute, (2) blood oxygen saturation $\leq 93 \%$ at rest, (3) $\mathrm{PaO} 2 / \mathrm{FiO} 2$ ratio $\leq 300$. Critical type met at least one of the following criteria: (1) respiratory failure with mechanical ventilation, (2) septic shock, (3) transferred to the intensive care unit due to multiple organ failure. Patients with acute coronary syndrome or acute heart failure at admission or in the latest one month were excluded. This study was approved by the Ethics Commission of Beijing Hospital (2020BJYYEC-035-01).

Laboratory confirmation of SARSCoV-2 was done by real-time RT-PCR. The protocol was the same as the document published recently [4]. We also examined other respiratory viruses with real-time RT-PCR, including influenza A virus (H1N1, H3N2, H7N9), influenza $B$ virus, respiratory syncytial virus, parainfluenza virus, adenovirus, SARS coronavirus (SARS-CoV), and MERS coronavirus (MERS-CoV). Sputum or endotracheal aspirates were obtained at admission for the identification of possible causative bacteria or fungi.

\section{Data collection}

We obtained demographic, illness history, physical examination, laboratory test, management, and outcome data from patients' medical records. Blood oxygen saturation was measured after oxygen therapy. In-hospital mortality were observed.

Laboratory tests were conducted within $24 \mathrm{~h}$ after admission, including a complete blood count, procalcitonin, interleukin-6, ferritin, coagulation profile, renal and liver function, hypersensitive troponin I (hsTnI), and $\mathrm{N}$-terminal-pro brain natriuretic peptide (NTproBNP).

\section{Table 1 Demographics and clinical characteristics of severe COVID-19}

\begin{tabular}{|c|c|}
\hline Variables & $\begin{array}{l}\text { Median (IQR), or N (\%) } \\
\text { Patients }(n=100)\end{array}$ \\
\hline \multicolumn{2}{|l|}{ Age, y } \\
\hline Median (IQR) & $62.0(51.0-70.8)$ \\
\hline$<60$ & $40(40.0)$ \\
\hline$\geq 60$ & $60(60.0)$ \\
\hline \multicolumn{2}{|l|}{ Sex } \\
\hline Male & $56(56.0)$ \\
\hline Female & $44(44.0)$ \\
\hline Comorbidities & $69(69.0)$ \\
\hline Hypertension & $40(40.0)$ \\
\hline Diabetes & $21(21.0)$ \\
\hline CVD & $15(15.0)$ \\
\hline COPD & $12(12.0)$ \\
\hline Malignancy & $13(13.0)$ \\
\hline Hypothyroidism & $2(2.0)$ \\
\hline Liver cirrhosis & $3(3.0)$ \\
\hline Hyperlipidemia & $2(2.0)$ \\
\hline Anemia & $2(2.0)$ \\
\hline \multicolumn{2}{|l|}{ Initial symptoms } \\
\hline Fever & $69(69.0)$ \\
\hline Cough & $63(63.0)$ \\
\hline Chest distress & $13(13.0)$ \\
\hline Fatigue & $12(12.0)$ \\
\hline Sputum & $7(7.0)$ \\
\hline Myalgia & $5(5.0)$ \\
\hline Dyspnea & $6(6.0)$ \\
\hline Headache & $4(4.0)$ \\
\hline Sore throat & $4(4.0)$ \\
\hline Chest pain & $2(2.0)$ \\
\hline Diarrhea & $3(3.0)$ \\
\hline Nausea & $3(3.0)$ \\
\hline $\mathrm{SBP}, \mathrm{mmHg}$ & $135.0(122.0-149.0)$ \\
\hline $\mathrm{DBP}, \mathrm{mmHg}$ & $81.5(74.8-91.0)$ \\
\hline Heart rate, bpm & $92.5(79.5-103.3)$ \\
\hline $\mathrm{SPO} 2, \%^{\S}$ & $97.0(95.0-98.0)$ \\
\hline$\leq 93.0$ & $10(10.0)$ \\
\hline Days from illness onset to admission & $14.0(7.0-28.0)$ \\
\hline Hospitalization time, day & $21.0(15.0-39.5)$ \\
\hline
\end{tabular}

$\S$ Oxygen saturation was measured on admission after receiving oxygen therapy. COVID-19= coronavirus disease 2019; COPD = chronic obstructive pulmonary disease; $\mathrm{CVD}=$ cardiovascular disease; $\mathrm{SBP}=$ systolic blood pressure; $\mathrm{DBP}=$ diastolic blood pressure 


\section{Definition of cardiac damage}

Cardiac damage was defined as plasma hsTnI over $34.2 \mathrm{pg} / \mathrm{ml}$ and/or NTproBNP above $450 \mathrm{pg} / \mathrm{ml}$ at the age age $<50$, above $900 \mathrm{pg} / \mathrm{ml}$ at the age $<75$, or above $1800 \mathrm{pg} / \mathrm{ml}$ at the age $\geq 75[11]$.

\section{Statistical analysis}

Continuous variables were expressed as mean \pm SD when they were normally distributed or median (IQR) when they were not, and compared with the $t$-test or MannWhitney U test, respectively; categorical variables were expressed as number (\%) and compared by $x^{2}$ test or Fisher's exact test. Logistic regression analysis was performed to identify variables with a significant independent association with cardiac damage. Demographics (age and sex), potential confounders (hypertension, diabetes, cardiovascular disease, and hyperlipidemia), and variables with $\mathrm{p} \leq 0.05$ in the univariate analysis were adjusted. A two-sided $\alpha$ of less than 0.05 was considered statistically significant. Statistical analyses were done using the SPSS software (version 23) for all analyses.

Table 2 Laboratory characteristics of severe COVID-19

\begin{tabular}{|c|c|}
\hline Variables & $\begin{array}{l}\text { Mean } \pm \text { SD, } \\
\text { Median (IQR), } \\
\text { or N (\%) }\end{array}$ \\
\hline White blood count, $\times 10^{9} / \mathrm{L}$ & $5.8(4.3-8.5)$ \\
\hline Neutrophil count, $\times 10^{9} / \mathrm{L}$ & $3.7(2.4-7.1)$ \\
\hline Lymphocyte count, $\times 10^{9} / \mathrm{L}$ & $1.1(0.7-1.6)$ \\
\hline Platelet count, $\times 10^{9} / \mathrm{L}$ & $211.5(164.0-301.0)$ \\
\hline Hemoglobin, $g / L$ & $119.2 \pm 20.2$ \\
\hline Prothrombin time, $s$ & $13.9(13.4-14.4)$ \\
\hline Activated partial thromboplastin time, $\mathrm{s}$ & $39.1(35.7-43.5)$ \\
\hline Fibrinogen, $g / L$ & $4.76 \pm 1.55$ \\
\hline D-dimer, mg/L & $1.1(0.4-3.5)$ \\
\hline Alanine aminotransferase, $U / L$ & $19.0(12.0-41.0)$ \\
\hline Creatinine, $\mu \mathrm{mol} / \mathrm{L}$ & $67.0(57.5-86.5)$ \\
\hline Procalcitonin, ng/ml & $0.07(0.03-0.10)$ \\
\hline Interleukin-6, pg/ml & $7.67(3.01-23.51)$ \\
\hline Ferritin, ng/ml & $559.3(304.7-1214.6)$ \\
\hline hsCRP, mg/ml & $11.6(2.6-47.1)$ \\
\hline Cardiac damage & $25(25.0)$ \\
\hline hsTnl, pg/ml & $3.5(1.9-11.2)$ \\
\hline Increased (> 34.2) & $9(9.0)$ \\
\hline NTproBNP, pg/ml & $133.5(42.3-369.5)$ \\
\hline Increased ${ }^{\#}$ & $22(22.0)$ \\
\hline Influenza A antibody & $5(5.0)$ \\
\hline
\end{tabular}

COVID-19 = coronavirus disease 2019; hsCRP = hypersensitive C-reactive protein; hsTnl = hypersensitive troponin I; NTproBNP $=\mathrm{N}$-terminal-pro brain natriuretic peptide. "Increased NTproBNP was above $450 \mathrm{pg} / \mathrm{ml}$ at the age $<50$, above $900 \mathrm{pg} / \mathrm{ml}$ at the age $<75$, or above $1800 \mathrm{pg} / \mathrm{ml}$ at the age $\geq 75$
Table 3 Age differences in cardiac damage in patients with severe type of COVID-19

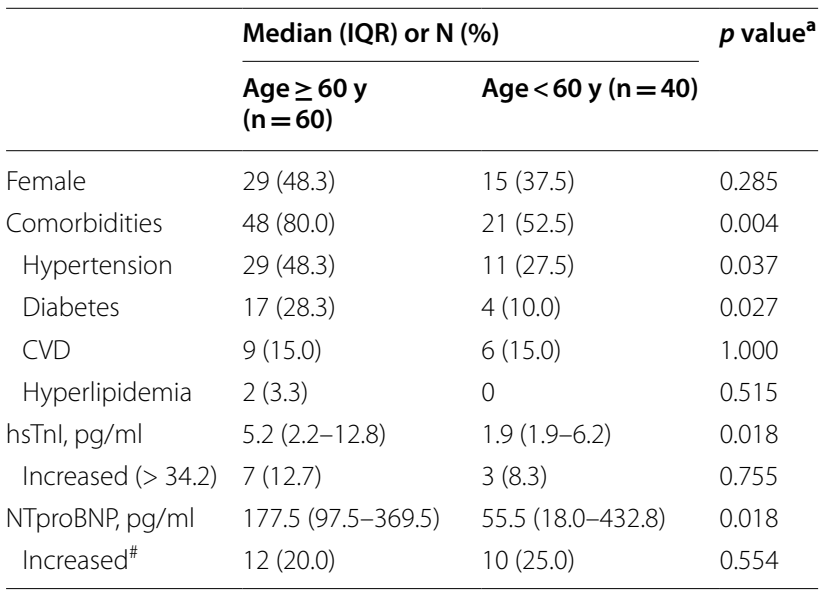

a $p<.05$ was considered statistically significant. COVID-19= coronavirus disease 2019; CVD = cardiovascular disease; $\mathrm{hsTnl}=$ hypersensitive troponin l; NTproBNP = N-terminal-pro brain natriuretic peptide. "Increased NTproBNP was above $450 \mathrm{pg} / \mathrm{ml}$ at the age $<50$, above $900 \mathrm{pg} / \mathrm{ml}$ at the age $<75$, or above $1800 \mathrm{pg} / \mathrm{ml}$ at the age $\geq 75$

Table 4 Sex differences in cardiac damage in patients with severe type of COVID-19

\begin{tabular}{llll}
\hline & \multicolumn{2}{l}{ Median (IQR) or N (\%) } & \multirow{2}{*}{ p Value $^{\mathbf{a}}$} \\
\cline { 2 - 3 } & Men (n= 56) & Women (n=44) & \\
\hline Age $\geq 60 y$ & $31(55.4)$ & $29(65.9)$ & 0.285 \\
Comorbidities & $34(60.7)$ & $35(79.5)$ & 0.043 \\
Hypertension & $18(32.1)$ & $22(50.0)$ & 0.070 \\
Diabetes & $9(16.1)$ & $12(27.3)$ & 0.172 \\
CVD & $5(8.9)$ & $10(22.7)$ & 0.055 \\
Hyperlipidemia & $1(1.8)$ & $1(2.3)$ & 1.000 \\
Cardiac damage & $18(32.1)$ & $7(15.9)$ & 0.063 \\
hsTnl, pg/ml & $4.2(1.9-12.8)$ & $2.9(1.9-7.4)$ & 0.018 \\
Increased $(>34.2)$ & $5(10.4)$ & $5(11.6)$ & 0.340 \\
NTproBNP, pg/ml & $272.5(57.0-559.8)$ & $86.0(31.3-209.3)$ & 0.013 \\
Increased & $18(32.1)$ & $4(9.1)$ & 0.006 \\
\hline
\end{tabular}

a $p<.05$ was considered statistically significant. COVID-19= coronavirus disease 2019; CVD = cardiovascular disease; hsTnl = hypersensitive troponin I; NTproBNP = N-terminal-pro brain natriuretic peptide. "Increased NTproBNP was above $450 \mathrm{pg} / \mathrm{ml}$ at the age $<50$, above $900 \mathrm{pg} / \mathrm{ml}$ at the age $<75$, or above $1800 \mathrm{pg} / \mathrm{ml}$ at the age $\geq 75$

\section{Results}

From February 8 to April 10, 2020, 100 laboratory-confirmed COVID-19 patients were classified as the severe type at the Sino-French New Town area, with an median age of 62.0 years old. 56 (56.0\%) cases were men. 69.0\% of the patients had comorbidities, of which hypertension, diabetes, and cardiovascular disease were the top three diseases. The initial symptoms were mainly fever, cough, chest distress, and fatigue. Ten patients had oxygen 
Table 5 Demographics and clinical characteristics of patients with and without cardiac damage

\begin{tabular}{|c|c|c|c|}
\hline \multirow[t]{2}{*}{ Variables } & \multicolumn{2}{|c|}{ Mean $\pm S D$, median $(\mathrm{IQR})$, or $\mathrm{N}(\%)$} & \multirow[t]{2}{*}{$p$ Value } \\
\hline & Cardiac damage $(n=25)$ & Non cardiac damage $(n=75)$ & \\
\hline Age, y & $71.0(52.0-79.5)$ & $62.0(49.0-67.0)$ & 0.084 \\
\hline Gender & & & 0.063 \\
\hline Male & $18(72.0)$ & $38(50.7)$ & \\
\hline Female & $7(28.0)$ & $37(49.3)$ & \\
\hline Comorbidities & $21(84.0)$ & $48(64.0)$ & 0.061 \\
\hline Hypertension & $18(72.0)$ & $22(29.3)$ & 0.000 \\
\hline Diabetes & $9(36.0)$ & $12(16.0)$ & 0.033 \\
\hline CVD & $7(28.0)$ & $8(10.7)$ & 0.075 \\
\hline COPD & $2(8.0)$ & $10(13.3)$ & 0.722 \\
\hline Malignancy & $5(20.0)$ & $8(10.7)$ & 0.391 \\
\hline Hypothyroidism & $1(4.0)$ & $1(1.3)$ & 0.439 \\
\hline Liver cirrhosis & 0 & $3(4.0)$ & 0.571 \\
\hline Hyperlipidemia & $1(4.0)$ & $1(1.3)$ & 0.439 \\
\hline Anemia & $2(8.0)$ & 0 & 0.061 \\
\hline $\mathrm{SBP}, \mathrm{mmHg}$ & $135.0(125.0-151.0)$ & $134.0(121.0-148.5)$ & 0.368 \\
\hline $\mathrm{DBP}, \mathrm{mmHg}$ & $82.0(76.0-90.0)$ & $81.0(72.5-92.0)$ & 0.596 \\
\hline Heart Rate, bpm & $89.3 \pm 16.9$ & $92.9 \pm 16.3$ & 0.351 \\
\hline $\mathrm{SPO} 2 \leq 93.0 \%{ }^{\S}$ & $5(20.0)$ & $5(6.7)$ & 0.124 \\
\hline Days from illness onset to admission & $10.0(4.0-23.5)$ & $14.0(8.0-28.0)$ & 0.152 \\
\hline Hospitalization time, day & $30.0(18.0-50.0)$ & $19.0(12.8-36.5)$ & 0.024 \\
\hline White blood count, $\times 10^{9} / \mathrm{L}$ & $7.6(4.6-10.5)$ & $5.5(4.0-7.3)$ & 0.020 \\
\hline Lymphocyte count, $\times 10^{9} / \mathrm{L}$ & $0.9(1.3-0.7)$ & $1.2(0.8-1.7)$ & 0.286 \\
\hline Platelet count, $\times 10^{9} / \mathrm{L}$ & $190.0(156.0-304.0)$ & $227.0(170.0-297.0)$ & 0.389 \\
\hline Hemoglobin, g/L & $115.1 \pm 27.3$ & $120.5 \pm 17.4$ & 0.381 \\
\hline Prothrombin time, $s$ & $14.3(13.5-15.4)$ & $13.9(13.3-14.2)$ & 0.029 \\
\hline Activated partial thromboplastin time, $\mathrm{s}$ & $39.2(37.2-45.4)$ & $39.1(35.7-42.2)$ & 0.566 \\
\hline Fibrinogen, $g / L$ & $4.88 \pm 1.70$ & $119.2 \pm 20.2$ & 0.681 \\
\hline D-dimer, mg/L & $2.44(1.03-8.29)$ & $1.01(0.40-2.69)$ & 0.008 \\
\hline Alanine aminotransferase, $\mathrm{U} / \mathrm{L}$ & $25.5(12.0-44.0)$ & $19.0(12.0-38.8)$ & 0.463 \\
\hline Creatinine, $\mu \mathrm{mol} / \mathrm{L}$ & $79.0(64.0-94.8)$ & $64.0(55.0-80.5)$ & 0.022 \\
\hline Procalcitonin, ng/ml & $0.08(0.05-0.23)$ & $0.06(0.03-0.09)$ & 0.013 \\
\hline Interleukin-6, pg/ml & $26.23(6.09-46.06)$ & $6.08(2.54-14.15)$ & 0.002 \\
\hline Ferritin, ng/ml & 669.2 (332.9-992.9) & $457.6(303.3-1292.6)$ & 0.773 \\
\hline $\mathrm{hsCRP}, \mathrm{mg} / \mathrm{ml}$ & $39.4(10.2-79.6)$ & $8(2.4-41.7)$ & 0.019 \\
\hline Influenza A antibody & $1(4.0)$ & $4(5.3)$ & 1.000 \\
\hline Death & 0 & $4(5.3)$ & 0.556 \\
\hline
\end{tabular}

$\S$ Oxygen saturation was measured on admission after receiving oxygen therapy. COVID-19= coronavirus disease 2019; COPD =chronic obstructive pulmonary disease; $\mathrm{CVD}=$ cardiovascular disease; $\mathrm{SBP}=$ systolic blood pressure; $\mathrm{DBP}=$ diastolic blood pressure; hsCRP $=$ hypersensitive $\mathrm{C}$-reactive protein

saturation below 93\% after nasal oxygen supply at admission (Table 1).

Cardiac damage occurred in 25 patients. (Table 2) Increased hsTnI was in $9(9.0 \%)$ patients; increased NTproBNP was in 22 (22.0\%) patients. Subgroup analysis showed that significant age and sex differences in hsTnI. (Tables 3,4 ) The elderly patients had higher plasma hsTnI levels, so did the males, who also had significantly higher NTproBNP levels than the females. Although NTproBNP level was far higher in the elder, the statistical difference disappeared when taking the effect of age on NTproBNP into consideration.

Patients with cardiac damage had a higher proportion of hypertension and diabetes, compared to those without 
Table 6 Logistic multivariable models for determinants of cardiac damage

\begin{tabular}{lllll}
\hline Variables & $\boldsymbol{\beta}$ & Adjusted HR & $\mathbf{9 5 \%} \mathbf{C l}$ & $\boldsymbol{p}$ Value \\
\hline Age & -0.01 & 0.99 & $0.93-1.06$ & 0.771 \\
Male & 1.63 & 5.09 & $1.19-22.17$ & 0.028 \\
Hypertension & 2.29 & 9.88 & $2.52-28.70$ & 0.001 \\
Diabetes & 0.90 & 2.46 & $0.36-17.00$ & 0.360 \\
Cardiovascular disease & 1.32 & 3.73 & $0.41-33.84$ & 0.242 \\
Hyperlipidemia & 1.46 & 4.32 & $0.04-530.45$ & 0.551 \\
White blood count & -0.04 & 0.96 & $0.79-1.18$ & 0.725 \\
Prothrombin time & 0.17 & 1.18 & $0.75-1.86$ & 0.468 \\
d-dimer & 0.16 & 1.18 & $0.97-1.43$ & 0.090 \\
Creatinine & 0.01 & 1.01 & $0.99-1.04$ & 0.309 \\
Interleukin-6 & -0.01 & 0.99 & $0.98-1.00$ & 0.994 \\
Procalcitonin & 0.91 & 2.49 & $0.14-43.54$ & 0.531 \\
hsCRP & 0.02 & 1.02 & $1.00-1.04$ & 0.125 \\
\hline
\end{tabular}

Adjusted for age, sex, hypertension, diabetes, cardiovascular disease, hyperlipidemia, white blood count, prothrombin time, d-dimer, creatinine, interleukin-6, procalcitonin, and hsCRP

Table 7 Treatment and outcomes for severe COVID-19

\begin{tabular}{ll}
\hline Variables & N (\%) \\
\hline Treatment & \\
Antiviral therapy & $92(92.0)$ \\
Antibiotic therapy & $35(35.0)$ \\
Traditional Chinese medicine & $62(62.0)$ \\
Clinical outcomes & \\
Discharge & $94(94.0)$ \\
Death & $4(4.0)$ \\
\hline
\end{tabular}

COVID-19= coronavirus disease 2019

cardiac damage. White blood count, prothrombin time, d-dimer, creatinine, interleukin-6, procalcitonin, and hsCRP levels were significantly different between the two groups. After adjusting for age, sex, hypertension, diabetes, cardiovascular disease, hyperlipidemia, and variables with significant differences, we found male and hypertension were the risk factors of cardiac damage in patients with severe COVID-19. (Tables 5, 6).

By the end of April 10, 2020, four (4.0\%) patients died. In the same period, 96 patients, of which 2 cases deteriorated to critical type but ultimately recovered and discharged from the hospital according to the Criteria of Diagnosis and Treatment of Pneumonia Infected by Novel Coronavirus (5th trial edition). (Table 7).

\section{Discussion}

In this retrospective study, we analyzed data from 100 patients with severe type of laboratory-confirmed COVID-19. Fever, cough, chest distress, and fatigue were common symptoms. Patients with severe COVID-19 also presented lymphopenia, elevated interleukin-6, procalcitonin, and D-dimer. These were consistent with recent researches [3, 4, 12, 13]. More than half of the patients had comorbidities, mainly including hypertension, diabetes, and cardiovascular disease. The prevalence of cardiac damage was $25 \%$. The mortality of severe COVID-19 was $4 \%$.

Huang et al. reported acute cardiac and kidney injuries in COVID-19 patients. In our study, one-quarter of the patients had cardiac damage, suggesting COVID-19 was a systemic disease and SARS-CoV-2 could cause multiorgan damage. The mechanism of cardiac damage resulted from SARS-CoV-2 is unclear. We consider two possible explanations: (1) immune response elicited by the coronavirus may lead to systemic inflammatory response $[14,15] ;(2)$ the virus exists in multiple organ systems to attack tissues [16].

The prevalence of elevated NTproBNP was $22.0 \%$ in our study, which was rarely reported previously. Published studies showed that the incidence of myocardial injury presenting elevated hsTnI was $7.2-19.7 \%$ in general COVID-19 patients and 23\% in critical ill patients, higher than $9.0 \%$ in our study $[9,10,17]$. It possibly owes to different criteria of elevated hsTnI, sample sizes, and the phases of COVID-19 breakout.

In subgroups, there was no significant age or sex difference in cardiac damage, but a higher proportion of comorbidities, especially hypertension and diabetes, existed in patients with cardiac damage. After multivariable analysis, we found males and hypertension were the risk factors of cardiac damage. It is consistent with Shi's report [10]. As all the patients in our study didn't have an acute coronary syndrome or acute heart failure at admission or in the latest one month, it may suggest that male patients with hypertension are more susceptible to cardiac damage. The possible mechanism is that hypertension-induced cardiac damage is associated with mitochondrial injury, which can be caused by SARS-COV-2 $[18,19]$. Estrogen may also play an important protective role in the process [20]. Researchers found cardiac troponins elevation was associated with the male [21, 22].

As of April 10, 96\% of the patients were discharged from the hospital. The mortality was $4 \%$, less than the average mortality of severe acute respiratory syndrome (SARS) and Middle Eastern respiratory syndrome (MERS), which were $11 \%$ and $35 \%$ [23, 24]. It indicates the prognosis of COVID-19 is generally good. There was 
no difference in mortality between patients with cardiac damage and those without ( 0 vs. $5.3 \%, p=0.556)$.

\section{Limitations}

Our study has several limitations. First, it's a study with a small sample size, confounding factors and selection bias are inevitable. Second, we had no data on medication history, electrocardiography, and echocardiography and we can't describe and discuss the results adequately. Third, we didn't include the outcomes after patients were discharged from the hospital.

\section{Conclusion}

COVID-19 is a systemic disease. Cardiac damage exists in patients with the severe type of COVID-19, especially in male patients with hypertension. Clinicians should pay more attention to cardiac damage. Further studies with large sample size are needed to verify our findings.

\footnotetext{
Abbreviations

SARS-CoV-2: Severe acute respiratory syndrome coronavirus 2; COVID-19: Coronavirus disease 2019;: SARS-CoV: SARS coronavirus; MERS-CoV: MERS coronavirus; hsTnl: Hypersensitive troponin I; NTproBNP: N-terminal-pro brain natriuretic peptide.
}

\section{Acknowledgments \\ None.}

\section{Authors' contributions}

All authors contributed to this work. $L J, G J$ and $L J$ conceived and designed the study; $\sqcup, Z Y H, G J$ and $L J$ analyzed the data and drafted the manuscript. All authors revised and approved the final manuscript.

\section{Funding}

The study was funded by the Beijing Municipal Natural Science Foundation (No. 7192078).

\section{Availability of data and materials}

The datasets used and/or analysed during the current study are available from the corresponding author on reasonable request.

\section{Ethics approval and consent to participate}

This study was approved by the Ethics Commission of Beijing Hospital (2020BJYYEC-035-01). Individual informed consent was waived by the ethics committee listed above because this study used currently existing sample collected during the course of routine medical care and did not pose any additional risks to the patients.

\section{Consent for publication}

Not applicable.

\section{Competing interests}

All authors have nothing to declare.

\section{Author details}

1 Division of Cardiology, Beijing Hospital, \#1 Dahua Road, Dongcheng District, Beijing 100730, China. ${ }^{2}$ Division of Cardiology, Xuanwu Hospital Capital Medical University, \#45 Changchun Street, Xicheng District, Beijing 100053, China. ${ }^{3}$ Division of Intensive Care Unit, Beijing Hospital, Beijing 100730, China. ${ }^{4}$ Division of Rheumatology and Immunology, Beijing Hospital, Beijing 100730, China. ${ }^{5}$ Division of Emergency, Beijing Hospital, Beijing 100730, China. ${ }^{6}$ National Center Research Center of Geriatric Diseases [Xuanwu Hospital], Beijing 100053, China.
Received: 15 July 2020 Accepted: 26 October 2020

Published online: 10 November 2020

\section{References}

1. 1ICTV. The species Severe acute respiratory syndrome-related coronavirus: classifying 2019-nCoV and naming it SARS-CoV-2. Nat Microbiol. 2020:5:536-44.

2. Chan JF, Yuan S, Kok K, To KK, Chu H, Yang J, et al. A familial cluster of pneumonia associated with the 2019 novel coronavirus indicating person-to-person transmission: a study of a family cluster. Lancet. 2020;395:514-23

3. $X u X, W u X$, Jiang $X, X u K$, Ying $L, M a C$, et al. Clinical findings in a group of patients infected with the 2019 novel coronavirus (SARS-Cov-2) outside of Wuhan, China: retrospective case series. BMJ. 2020;368:m606.

4. Huang C, Wang Y, Li X, Ren L, Zhao J, Hu Y, et al. Clinical features of patients infected with 2019 novel coronavirus in Wuhan China. Lancet. 2020;395:497-506.

5. Sun K, Chen J, Viboud C. Early epidemiological analysis of the coronavirus disease 2019 outbreak based on crowdsourced data: a population-level observational study. Lancet Dig Health. 2020;2:e201-8.

6. 6WHO COVID-19 Dashboard.2020. https://covid19.who.int/ Accessed 1 May, 2020

7. 7China NHCO. The Diagnosis and Treatment of Pneumonia Infected by Novel Coronavirus (5th trial edition). 5 February, 2020. https ://39.137.20.198/cache/www.nhc.gov.cn/xcs/zhengcwj/202002/3b09b 894ac9b4204a79db5b8912d4440/files/7260301a393845fc87fcf6dd5 2965ecb.pdf?ich_args2=46-24145100054382_b8ed1a1a481d778c4350 3cdcde88e45c_10001002_9c896c2ed2c1f6d1913c518939a83798_10cab ae9adc42948a617b3b1c71d6fff. Accessed 24 February, 2020

8. Team TNCP. The epidemiological characteristics of an outbreak of 2019 novel coronavirus disease (COVID-19) in China. Chin J Epidemiol. 2020;41:145-51.

9. Wang D, Hu B, Hu C, Zhu F, Liu X, Zhang J, et al. Clinical characteristics of 138 hospitalized patients with 2019 novel coronavirus-infected pneumonia in Wuhan China. JAMA. 2020;323:1061-9.

10. 10Shi S, Qin M, Shen B, Cai Y, Liu T, Yang F, et al. Association of cardiac injury with mortality in hospitalized patients WithCOVID-19 in Wuhan, China. JAMA Cardiol. 2020;e200950.

11. Chinese Medical Association. Chinese Medical Journals Publishing House, Chinese Society of General Practice, Editorial Board of Chinese Journal of General Practitioners of Chinese Medical Association, Expert Group of Guidelines for Primary Care of Cardiovascular Disease. Guideline for primary care of acute heart failure. Chin J Gen Pract. 2019;18:925-30.

12. Chen N, Zhou M, Dong X, Qu J, Gong F, Han Y, et al. Epidemiological and clinical characteristics of 99 cases of 2019 novel coronavirus pneumonia in Wuhan, China: a descriptive study. Lancet. 2020;395:507-13.

13. Guan W, Ni Z, Hu Y, Liang W, Ou C, He J, et al. Clinical characteristics of coronavirus disease 2019 in China. N Engl J Med. 2020;382:1708-20.

14. Fu Y, Cheng Y, Wu Y. Understanding SARS-CoV-2-mediated inflammatory responses: from mechanisms to potential therapeutic tools. Virol Sin. 2020:35:266-71.

15. Rokni M, Ghasemi $V$, Tavakoli Z. Immune responses and pathogenesis of SARS-CoV-2 during an outbreak in Iran: comparison with SARS and MERS. Rev Med Virol. 2020;30:e2107.

16. Wang W, Xu Y, Gao R, Lu R, Han K, Wu G, Tan W. Detection of SARS-CoV-2 in different types of clinical specimens. JAMA. 2020;323:1843-4.

17. Yang $X, Y u Y, X u J$ J, Shu $H, X i a ~ J, ~ L i u ~ H$, et al. Clinical course and outcomes of critically ill patients with SARS-CoV-2 pneumonia in Wuhan, China: a single-centered, retrospective, observational study. Lancet Respirat Med. 2020;8:475-81.

18. Eirin A, Lerman A, Lerman LO. Mitochondrial injury and dysfunction in hypertension-induced cardiac damage. EUR HEART J. 2014;35:3258-66.

19. Saleh J, Peyssonnaux C, Singh KK, Edeas M. Mitochondria and microbiota dysfunction in COVID-19 pathogenesis. MITOCHONDRION. 2020;54:1-07.

20. Patrizio M, Marano G. Gender differences in cardiac hypertrophic remodeling. Ann Ist Super Sanita. 2016;52:223-9. 
21. Suthahar N, Meems LMG, Ho JE, de Boer RA. Sex-related differences in contemporary biomarkers for heart failure: a review. Eur J Heart Fail. 2020;22:775-88

22. Wallace TW, Abdullah SM, Drazner MH, Das SR, Khera A, McGuire DK, et al. Prevalence and determinants of troponin T elevation in the general population. Circulation. 2006;113:1958-65.

23. Chan KS, Zheng JP, Mok YW, Li YM, Liu YN, Chu CM, Ip MS. SARS: prognosis, outcome and sequelae. Respirology. 2003:8(Suppl):S36-40.
24. Badawi A, Ryoo SG. Prevalence of comorbidities in the middle east respiratory syndrome coronavirus (MERS-CoV): a systematic review and meta-analysis. Int J Infect Dis. 2016;49:129-33.

\section{Publisher's Note}

Springer Nature remains neutral with regard to jurisdictional claims in published maps and institutional affiliations.
Ready to submit your research? Choose BMC and benefit from:

- fast, convenient online submission

- thorough peer review by experienced researchers in your field

- rapid publication on acceptance

- support for research data, including large and complex data types

- gold Open Access which fosters wider collaboration and increased citations

- maximum visibility for your research: over $100 \mathrm{M}$ website views per year

At BMC, research is always in progress.

Learn more biomedcentral.com/submissions 